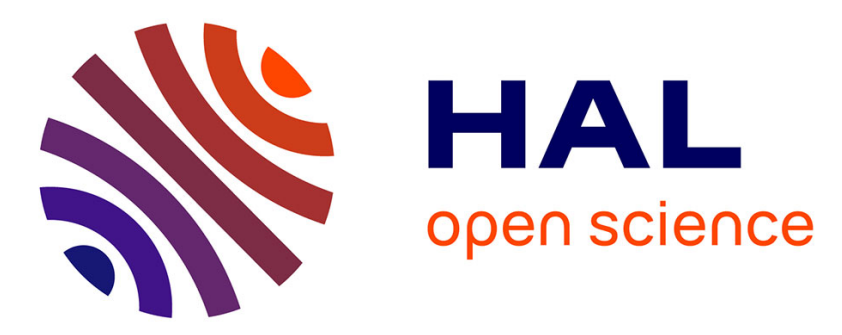

\title{
Can the emotional connotation of concepts modulate the lexico-semantic deficits in Alzheimer's disease?
}

Bénédicte Giffard, Mickaël Laisney, Francis Eustache, Béatrice Desgranges

\section{To cite this version:}

Bénédicte Giffard, Mickaël Laisney, Francis Eustache, Béatrice Desgranges. Can the emotional connotation of concepts modulate the lexico-semantic deficits in Alzheimer's disease?: Emotion and semantic memory in Alzheimer's disease. Neuropsychologia, 2009, 47 (1), pp.258-67. 10.1016/j.neuropsychologia.2008.07.013 . inserm-00538385

\section{HAL Id: inserm-00538385 https://www.hal.inserm.fr/inserm-00538385}

Submitted on 22 Nov 2010

HAL is a multi-disciplinary open access archive for the deposit and dissemination of scientific research documents, whether they are published or not. The documents may come from teaching and research institutions in France or abroad, or from public or private research centers.
L'archive ouverte pluridisciplinaire HAL, est destinée au dépôt et à la diffusion de documents scientifiques de niveau recherche, publiés ou non, émanant des établissements d'enseignement et de recherche français ou étrangers, des laboratoires publics ou privés. 
Can the emotional connotation of concepts modulate the lexico-semantic deficits in Alzheimer's disease?

Bénédicte Giffard,* Mickaël Laisney, Francis Eustache, Béatrice Desgranges

Inserm - EPHE - Université de Caen/Basse-Normandie, U923, GIP Cyceron, CHU Côte de Nacre, Caen, France

* Corresponding author: B. Giffard, Inserm - EPHE - Université de Caen Basse Normandie, Unité U923, Esplanade de la Paix, UFR de Psychologie, 14032 Caen Cedex, France. Tel: + 33 2315662 79, Fax: + 332315666 93, e-mail: benedicte.giffard@unicaen.fr

Brief running title: Emotion and semantic memory in Alzheimer's disease 


\begin{abstract}
Semantic memory impairments are a common symptom of Alzheimer's disease (AD) and may occur at a relatively early stage. These disturbances can be evidenced by a hyperpriming effect (greater semantic priming in AD patients than in controls). Up to now, very few studies of semantic memory have included emotionally charged concepts. Our aim was therefore to study the semantic processing of such concepts, as opposed to neutral ones, in early AD. Given that emotional processes are relatively preserved at the beginning of the disease compared with other cognitive functions, we expected that an emotional connotation would influence the spreading activation of words and affect some of the impairments in semantic processing. We administered a semantic priming task (lexical decision task) implicitly assessing semantic memory to 26 patients with $\mathrm{AD}$ and 26 normal controls. Primes and targets either had a semantic relationship (e.g. tiger-lion), a semantic and emotional (positive or negative) relationship (e.g. slap-smack) or no relationship at all (e.g. chair-horse), or else belonged to a word-nonword condition (e.g. window-inuly). Compared with controls, the patients showed pathological hyperpriming effects in all conditions, especially in the emotional conditions. Hyperpriming implies a deterioration in specific attributes, as it is difficult to tell two concepts apart once their distinctive attributes have been lost. These results suggest that emotional concepts, like neutral ones, lose some of their distinctive attributes in early $\mathrm{AD}$, and as the emotional processes are preserved, there is greater similarity between close emotional concepts than between close neutral concepts.
\end{abstract}




\section{Introduction}

Semantic memory impairments are frequently observed in patients suffering from Alzheimer's disease (AD) (see Hodges, 2006), even in the early stages of the disease. These deficits are often attributed to a deterioration in concepts (symbolic representations of world knowledge stored in semantic memory) (Hodges, Salmon, \& Butters, 1992; Salmon Butters, \& Chan, 1999). However, this breakdown is progressive and apparently partial, as superordinate concepts are frequently preserved, unlike subordinate information (Martin \& Fedio, 1983). The tasks that are often used to assess semantic memory are not, however, specific and draw on cognitive processes other than semantic processing (sustained attention, active searching, executive processes, etc.) that are often disturbed in AD. Another method, used in numerous AD studies to investigate semantic memory, rests on the semantic priming paradigm. Here, semantic priming effects are highlighted when a target (e.g. chair) in a lexical decision or pronunciation task, is recognised faster if it is preceded by a semanticallyrelated prime (e.g. table) than by an unrelated one (e.g. horse) (see Neely, 1991; Lucas, 2000; Hutchinson, 2003, for reviews). This processing facilitation generally depends on the automatic spreading of activation through the semantic network (Collins \& Loftus, 1975): the presentation of a prime automatically activates its node in memory, and this activation then spreads to related nodes, thus momentarily increasing their accessibility. Therefore, when the prime and target are related, the target word is likely to have undergone this prior activation and will be recognised more quickly. It is this automatic pre-activation of related words in the semantic network that is thought to be the cause of the observed facilitation. The semantic priming paradigm is assumed to be an implicit measurement of semantic memory: it is an experimental paradigm that minimises the effect of strategic confounds and thus provides a means of assessing semantic memory in a more automatic manner than classic semantic tasks. 
Semantic priming studies in AD have yielded contradictory results (e.g. Chertkow, Bub, \& Seidenberg, 1989; Nebes, Martin, \& Horn, 1984; Silveri, Monteleone, Burani, \& Tabossi, 1996; see Giffard, Desgranges, \& Eustache, 2005, for a review). Recently, a longitudinal study clearly revealed changing patterns of priming effects over the course of $\mathrm{AD}$, depending on the degree of semantic memory deterioration (Giffard et al., 2002). In this study, in order to assess different levels of the semantic structure, related pairs of words were given either a coordinate relationship (e.g. tiger-lion, where the prime and target belong to the same semantic category and share the same semantic level) or an attribute one (e.g. tiger-stripes, where the target is a semantic attribute of the prime). In the coordinate condition, priming effects increased abnormally (hyperpriming) at the beginning of the process of semantic deterioration, i.e. when the specific attributes of concepts (e.g. stripes, mane, etc.) start to be lost. When concept attributes begin to deteriorate - unlike superordinate information, which is well preserved (e.g. AD patients still know that tigers and lions are wild animals, but no longer have any knowledge about their stripes and manes) - the ability to distinguish between two coordinate concepts is impaired. Accordingly, in the coordinate relationship, priming effects not only exist - since the words are still semantically related through membership of their preserved superordinate class - but are greater than those in the control group (hyperpriming), because the specific attributes characterising each concept have been lost (e.g. the tiger's stripes, the lion's mane). This brings confusion, an overlapping of the two coordinate concepts (both are wild animals, both have fur and both are dangerous). Accordingly, as suggested by Martin (1992), what should be semantic priming (tiger-lion) turns into repetition priming (wild animal - wild animal), with larger effects than the former. Thereafter, as semantic memory deteriorates still further, these priming effects decrease, because not only are the specific attributes gradually impaired but also the overall meaning of each concept (Giffard et al., 2001), with the result that the two coordinate concepts become 
less semantically close. In the attribute condition, we should have observed a decrease in semantic priming in our previous study at the onset of deterioration (attribute level), with patients displaying hyperpriming in the coordinate condition. In actual fact the attribute priming scores remained normal. This can be ascribed to the fact that, in $\mathrm{AD}$, concept attributes or features are not lost in an all-or-nothing manner; rather, the loss is gradual and incomplete at the start of the disease. This pattern of results is well-explained in connectionist models, which assume that category structure is based on similarity and the degree to which semantic features overlap (e.g. McRae et al., 1997). Thus, "tiger" and "lion" are coordinate concepts (i.e. they belong to the same category, animal, and are semantically close) because they share a large number of category-relevant features (e.g. wild, four legs, fur; i.e. common features). Other features, however, allow them to be told apart (e.g. the tiger's stripes and the lion's mane; i.e. distinctive or specific features). In $\mathrm{AD}$, common features appear to be preserved longer than distinctive features (Devlin, Gonnerman, Andersen, \& Seidenberg, 1998). Our previous studies therefore revealed normal attribute priming scores because the attribute condition was mainly composed of common features (Giffard et al., 2001, 2008).

Whereas the literature about semantic memory disorders in AD patients is very extensive, only a few studies have looked at the ability of patients to process emotional concepts. This may be linked to the fact that the cognitive models of semantic memory have not really sought to differentiate emotional concepts from neutral ones, thus making investigations difficult to integrate into well-established theoretical accounts. Yet, in young normal subjects, several affective priming studies have shown that, like the semantic relationship, the emotional relationship between a prime (e.g. kiss) and a target (e.g. sunshine) without any semantic or associative relationship, leads to a facilitation effect (Innes-Ker \& Niedenthal, 2002; Wentura, 1999; Versace, Augé, Thomas Antérion, \& Laurent, 2002; Pecchinenda, Ganteaume, \& Banse, 2006; see Klauer \& Musch, 2003, for a review). This affective priming 
effect could be compatible with the automatic spreading activation account and suggests, for some authors, that affective information is stored within the semantic system (De Houwer, Hermans, Rothemund, \& Wentura, 2002; Fazio, Sanbonmatsu, Powell, \& Kardes, 1986; Hermans, De Houwer, \& Eelen, 1994). An event-related potentials study conducted by Zhang, Lawson, Guo and Jiang (2006) showed that the N400 component is sensitive not only to semantic mismatches, but also to affective ones for prime-target pairs, suggesting that emotional connotations modulate word processing in the semantic network in a way similar to automatic spreading activation. Furthermore, in an fMRI study, Schirmer, Zysset, Kotz and von Cramon (2004) demonstrated that affective incongruity and semantic incongruity activate similar brain regions. This conception has, however, been widely challenged, with some authors arguing that affective priming effects are not semantic in nature and cannot therefore depend on a form of automatic spreading activation (Bargh, Chen, \& Burrows, 1996). They point out that as the automatic spreading of activation from one concept to another depends in part on the number of semantic features shared by the concepts (i.e. common features), it is difficult to explain how "sunshine" can prime "smile", given that the affective value is the only feature common to both words. According to this second standpoint, affective information is processed by a dedicated affective system which is quite distinct from the semantic system (LeDoux, 1992; Murphy \& Zajonc, 1993), even though the two systems are probably interconnected (Ferrand, Ric, \& Augustina, 2006). Due to this divergence of theories, targeted paradigms have yet to be constructed in order to determine the most appropriate explanatory model of affective priming effects. Although the priming paradigm used in the present study was constructed not for this purpose, but rather to improve our understanding of semantic deficits in $\mathrm{AD}$, these models nevertheless need to be mentioned, as they clearly demonstrate the influence of the emotional connotation of words on semantic processing. 
Furthermore, the diversity of affective priming paradigms in the literature may add to the conflict between explanatory models of affective priming, in that these paradigms do not always refer to the same processes. Some studies are based on "pure" affective priming (i.e. without any other relationship between the prime and the target, e.g. kiss-sunshine), whereas others use pairs of words that are related both semantically and affectively (e.g. coffincemetery). In the present study, we adopted the latter paradigm (semantic priming of emotional words vs. neutral words), taking the view that in emotional words, as opposed to neutral words, the affective components supplement the semantic features (e.g. the concept "viper" has a negative affective value and is composed of several semantic features: it slithers, is generally small and has a V on its head). Numerous authors have argued that the emotional dimension has a unique status compared with semantic features (e.g. Bargh, 1997; Zajonc, 1980), notably because emotional reactions can be evoked with minimum stimulus input. In a subliminal priming experiment with masked emotional words, Naccache et al. (2005) recorded brain potentials in the amygdala in three epileptic patients using intracranial electrodes. The authors found that the subliminal presentation of emotional words modulated the activity of the patients' amygdala. This could mean that, compared with neutral words, the enhancement of emotional word processing depends on the activation of the amygdala prior to conscious access via emotional components (valence, arousal, etc.). This nonconscious extraction of the meaning of emotional words would amplify cortical processing, thus increasing the probability of crossing a minimum threshold of neuronal activation subserving conscious access (Gaillard et al., 2006).

In $\mathrm{AD}$, the field of emotions started to receive attention in the last decade and represents a promising line of research which could lead to improvements in communication between patients and caregivers. The affective value of concepts could shore up the semantic memory deficits that are sometimes observed at an early stage in AD patients. Emotional processes 
(perception, comprehension or expression of emotions) are thought to be relatively preserved at the beginning of the disease, compared with other cognitive domains, such as semantic memory (Albert, Cohen, \& Koff, 1991; Bucks \& Radford, 2004). For example, AD patients seem to retain their ability to understand emotion, regardless of their generally lowered cognitive ability, and remain able to engage in nonverbal communication in interpersonal relationships (Budson et al., 2006).

Our objective in the present study was to introduce and control the emotional nature of concepts in order to conduct a more ecological investigation of semantic memory in AD using a semantic and affective priming paradigm. More specifically, we wanted to ascertain whether affective connotations can influence the automatic spreading activation of words in AD and affect some of the AD-related impairments in the semantic processing of words. To this end, we administered a lexical decision task comparing the automatic semantic priming effects of emotional (positive or negative) and neutral words to AD patients and normal controls. Primes and targets either shared a semantic relationship (e.g. table-chair), a semantic and emotional relationship (e.g. slap-smack), no relationship at all (e.g. pencil-horse), or else belonged to a word-nonword condition (e.g. window-inuly).

In the light of previous semantic priming studies involving non-emotional words (Giffard et al., 2001, 2002), we expected to observe a hyperpriming effect of concepts without an emotional relationship in the $\mathrm{AD}$ group (if they were in the early stages of semantic deterioration, i.e. with loss of specific attributes). Given that emotional words are processed effortlessly and automatically (Kissler et al., 2008) and that emotional processing is preserved in $\mathrm{AD}$, at first glance, one might assume that emotional concepts are more robust than neutral ones. Therefore, concerning concepts with both semantic and emotional relationship, semantic priming scores should be comparable to those of controls (i.e. less pathological and lower than semantic priming of non-emotional words). However, this theoretical view does not take 
into account the dynamic nature of semantic memory deterioration and the real meaning of hyperpriming, a phenomenon stemming from the loss of distinctive attributes combined with the preservation of common attributes. We therefore formed another hypothesis, considering that semantically close emotional words would, at the same time, lose some of their own specific attributes (just like non-emotional words) and share an additional common feature (i.e., the same emotional connotation). For this reason, we expected the semantic priming effects of emotional words to be larger than those of neutral ones (i.e. greater hyperpriming), given that the prime and the target would share the same emotional connotation. This common feature would reinforce the similarity between semantically close emotional words, thereby increasing the automatic spreading of activation. In the control group, as emotional word content is processed effortlessly and automatically, we would also observe larger priming effects when the concepts were emotional than when they were neutral.

In this lexical decision task, we used automaticity criteria to minimise the intervention of attentional mechanisms, such as prelexical expectancy or postlexical semantic matching processes: (i) low proportion of related word pairs (20\%); (ii) short stimulus-onset asynchrony or SOA (250 ms); (iii) low attention to the prime (the subject just had to respond to the target); and (iv) the same proportions of word and nonword targets (Posner \& Snyder, 1975; see Neely, 1991, for a review). Moreover, we controlled for the effects of the cognitive slowing process - a characteristic of AD patients - with the help of a measurement expressed as a percentage of the priming effects, in order to assess semantic priming for each patient on the basis of his/her own slowing.

\section{Method}

\subsection{Subjects}


Twenty-six patients were examined ( 11 men and 15 women; age $75.7 \pm 4.5$ years; range 6684 years). We purposely selected probable AD patients with mild-to-moderate dementia (McKhann et al., 1984), and administered a neuropsychological assessment to them which included the Mini Mental Status Examination (MMSE, Folstein, Folstein, \& McHugh, 1975; $22.8 \pm 2$; range 19-27) and the Dementia Rating Scale (DRS, Mattis, 1976; $120.3 \pm 4.8$; range 109-127). The patients gave their consent to the study after they had been provided with detailed information and the study was conducted in line with the Declaration of Helsinki.

A group of 26 healthy elderly subjects ( 11 men and 15 women; age $74.5 \pm 4.9$ years; range 65-83 years) were matched according to age and education with the AD patients ( $p=$ 0.34 and $p=0.39$ respectively). They had no neurological or psychiatric disorders and their MMSE (29.2 \pm 1 ; range 27-30) and DRS (138.5 \pm 3.3 , range 133-144) scores were significantly higher than those of the $\mathrm{AD}$ group ( $p<0.0001$ for both comparisons).

A French translation of Izard's emotional self rating scale (Differential Emotions Scale) (Ouss, Carton, Jouvent, \& Wildocher, 1990) showed no significant difference between the patients and controls concerning the perception of positive and negative emotions $(p=0.31$ and $p=0.11$ respectively).

\subsection{Stimuli}

The lexical decision task was composed of 270 pairs of stimuli: 30 pairs with a semantic relationship between neutral words (e.g. box-package), positive words (e.g. crib-baby) or negative words (e.g. cut-gash); 105 pairs without any semantic relationship between a neutral prime and a neutral target (e.g. chair-roof), a positive target (e.g. plate-kiss), or a negative target (e.g. house-viper); and 135 word/nonword pairs (e.g. shoe-bertin). To minimise the intervention of postlexical attentional processes, the likelihood of encountering a word versus a nonword in the target position was $50 \%$. In the pairs where the target was a word, $20 \%$ were 
semantically related, but $80 \%$ shared no semantic, associative or emotional link, thereby helping to prevent subjects from anticipating the nature of the target.

To select these word pairs, a series of meticulous pre-tests was conducted. First, 136 healthy volunteers aged 50 to 91 years had to judge the affective valence of 575 words on a scale of 1-8 (1: highly negative, 8 : highly positive) and write the first three words that came into their heads when they saw the words. From these data, we then selected the word pairs for the lexical decision task. All the semantically-related words were homogeneous in terms of their association frequency, with no extreme values in any condition. Only the most positively-, negatively- and neutrally-rated words were chosen. Between each related and unrelated condition, the words were balanced in terms of length and lexical frequency (Lexique, New, Pallier, Ferrand, \& Matos, 2001); most of the words were concrete in all conditions.

In a second pre-test designed to ensure that response times (RTs) on targets - not preceded by primes - were comparable for semantically-related and unrelated conditions, we administered a simple lexical decision composed of targets only to 10 other healthy subjects (60-83 years old): they had to decide as fast as possible whether the 384 targets presented successively were French words or not. The nonwords, all pronounceable, were created by replacing one letter per syllable of a real word taken from French word association norms. Three separate analyses of variance performed on the data of the neutral, positive and negative targets, comparing RTs on target words previously selected to form related pairs and RTs on targets from unrelated pairs, failed to reveal any significant differences. Significant priming effects could therefore be attributed to the influence of the prime on the target, and not to uncontrolled target variables.

Lastly, every positive and negative word was judged in terms of arousal (soothing or arousing effect of stimulus) by a separate group of 50 healthy subjects aged 56 to 78 years. 
They had to rate the words on a scale of 1-8 (1: highly soothing; 8: highly arousing). These 50 participants also rated the emotional words in terms of valence and their ratings matched those of the 136 volunteers in the first pre-test: the rates for the positive and negative words (valence: $6.74 \pm 0.39 ; 2.07 \pm 0.82$, respectively) were statistically equal in terms of absolute valence (i.e. distance from neutral valence) $[\mathrm{F}(1,88)=1.17 ; p=0.28]$. A one-factor ANOVA comparing arousal rates of emotional words showed that arousal by negative words was significantly greater than arousal by positive words $(6.25 \pm 0.63 ; 3.16 \pm 0.85$, respectively) $[\mathrm{F}(1,88)=379.6 ; p<0.0001]$. Nor were negative and positive words equal in terms of absolute arousal (i.e. distance from neutral arousal: 4.5) $[\mathrm{F}(1,88)=5.86 ; p=.017]$. The word pairs and their main characteristics are presented in the Appendix.

\subsection{Procedure}

The computerised, visual task was run individually. Stimuli were presented using Superlab 1.68 software (Cedrus Corporation, Phoenix, AZ, United States) which allows RTs to be measured accurately to within $1 \mathrm{~ms}$. During each trial, the subject was shown a fixation point on the screen for $500 \mathrm{~ms}$, followed by a prime word for $200 \mathrm{~ms}$. Thereafter, the screen remained empty for $50 \mathrm{~ms}$. SOA was $250 \mathrm{~ms}$ - too short an interval for the subject to anticipate the nature of the target. Subsequently, the target stimulus was displayed until a response was forthcoming. The screen then remained empty for 1,500 ms before the next trial began. In order to enhance the automaticity of the task, subjects were instructed to respond to the target as follows: if they recognised a French word in the series of letters, they had to press the "yes" key as fast as possible with their dominant hand; if the target did not mean anything to them, they had to press the "no" key with their other hand.

The task was divided into four blocks, each lasting approximately 5 minutes and separated by a few minutes' interval. Immediately beforehand, 30 practice trials were run in order to familiarise the subject with the task. 
On the basis of the RTs in each condition, three priming effects were assessed: semantic priming with non-emotional words (RTs for neutral targets in unrelated condition vs. RTs for neutral targets in related condition, e.g. chair-roof vs. box-package), semantic priming with positive words (RTs for positive targets in unrelated condition vs. RTs for positive targets in related condition, e.g. plate-kiss vs. crib-baby), and semantic priming with negative words (RTs for negative targets in unrelated condition vs. RTs for negative targets in related condition, e.g. house-viper vs. cut-gash). These priming effects were expressed as a percentage for each subject (priming effect divided by mean RT for the unrelated condition $\mathrm{x}$ 100). This approach helped to avoid a slowing effect on the priming (see Giffard et al., 2001; Giffard, Desgranges, Kerrouche, Piolino, \& Eustache, 2003, for details): Alzheimer's patients are characterised by an overall slowing of cognitive processes. Slower processing of words is thought to increase the facilitation effect, because a long processing time gives the semantic context more of a chance to have an effect. According to this argument, an increase in semantic priming effects may simply be an artefact of a general slowdown: the slower the participant, the larger the priming effects. A participant with a very long RT in the control condition (e.g. tiger-hammer) is more likely to display a large decrease in RT when the target is preceded by a related prime (e.g. tiger-lion) than a participant who performed faster in the control condition. Turning raw scores into percentages avoids this problem.

\section{Results}

In keeping with other studies of semantic priming effects in AD (Ober, Shenaut, Jagust, \& Stillman, 1991; Chertkow et al., 1994), we only report results for "yes" responses. In order to ensure that performances were not influenced by extreme scores, in each condition, response latencies that were more than 3 standard deviations (S.D.) from each participant's mean were treated as outliers and the mean was recalculated. Likewise, errors were excluded from the RT 
analyses. The accuracy scores are reported in Table 1. A two-way ANOVA: 2 groups (AD, controls) x 3 types of target (related words, unrelated words, nonwords) failed to show any significant difference between the groups of subjects $[\mathrm{F}(1,50)=1.79 ; p=0.19]$ or any significant group $\mathrm{x}$ type of target interaction $[\mathrm{F}(2,100)=0.01 ; p=0.99]$. We did, however, observe a significant effect of type of target $[\mathrm{F}(2,100)=3.41 ; p=0.04]$, as a post-hoc analysis (PLSD Fisher's test) revealed significantly more errors on nonwords than on related words $(p=0.01)$.

Insert Table 1

In order to determine whether the priming effects were significant and whether they were the result of slower or faster RTs, we conducted analyses on RTs recorded in each related and unrelated condition. The mean RTs for the correct responses (Table 2) were submitted to a three-way ANOVA: 2 groups (AD, controls) x 2 semantic conditions (related, unrelated) x 3 affective conditions (neutral, positive, negative). The analysis showed a significant effect of group $[\mathrm{F}(1,50)=21.68 ; p<0.0001]$ indicating that, as expected, the RTs of the AD patients were longer overall than those of the control group. There was also a significant effect of the semantic condition $[\mathrm{F}(1,50)=125.55 ; p<0.0001]$, the responses in the related conditions being faster than in the unrelated conditions. A significant group $\mathrm{x}$ semantic condition interaction was observed $[\mathrm{F}(1,50)=12.39 ; p=0.0009]$ and a post-hoc analysis (PLSD Fisher's test) showed that the difference in RTs for related and unrelated words was greater for the $\mathrm{AD}$ group $(p=0.029)$ than for the control group $(p=0.051)$. We observed a main effect of the affective condition $[\mathrm{F}(2,50)=4.39 ; p=0.015]$ and a significant semantic condition $\mathrm{x}$ affective condition interaction $[\mathrm{F}(2,100)=4.96 ; p=0.009]$, indicating that, for both groups, the most significant difference between RTs in the related and unrelated 
conditions concerned the negative valence condition. Whereas no significant difference in RTs was found between affective valences in related conditions, RTs in unrelated conditions were significantly longer for the negative valence than for the neutral $(p<0.0001)$ and positive ones $(p=0.0003)$. Conversely, the group $\mathrm{x}$ affective condition interaction was not significant $[\mathrm{F}(2,100)=1.2 ; p=0.30]$, demonstrating that the affective condition effect was similar for both patients and controls.

Insert Table 2

Semantic priming effects (Figure 1) were significant in both groups of subjects (as attested by the significant differences between RTs in the unrelated and related conditions for each affective condition). A two-way ANOVA: 2 groups (AD, controls) x 3 affective conditions (neutral, positive, negative) revealed a main effect of group $[\mathrm{F}(1,50)=4.96 ; p=$ 0.03], showing that the AD group displayed significantly greater priming effects (hyperpriming) than the controls. The effect of affective condition was also significant $[\mathrm{F}(2,50)=4.48 ; p=0.01]$. More specifically, the negative priming effects were significantly greater than those of the neutral $(p=0.006)$ and positive words $(p=0.04)$. The group $\mathrm{x}$ affective condition interaction was not significant.

\section{Insert Figure 1}

\section{Discussion}

The present findings reveal that, in both groups of subjects, semantic priming effects for neutral concepts existed but were smaller than those for emotional concepts, especially 
negative ones. This result may reflect a facilitation effect of the supplementary emotional component on the semantic processing which has previously been demonstrated by De Houwer et al. (2002) and Wentura (1999) in healthy young subjects and by Padovan et al. (2002) in normal elderly subjects. On the basis of the automatic spreading activation account, De Houwer et al. (2002) attributed their results to the more rapid activation of the target when preceded by an emotionally and semantically-related prime. According to distributed models of semantic priming, the extent to which automatic semantic priming occurs is directly related to the degree of similarity between the patterns of activation of the two relevant concepts, i.e. the greater the overlap of the activation patterns of the prime and the target, the stronger the semantic priming effects.

In the present study, we added an affective component, which strengthened the similarity between the concepts, and found that semantic priming effects were greater for the negative concepts than for the neutral and positive ones. Statistical analyses of the RTs clearly showed that neither in the AD group nor in the control group could the increased semantic priming for negative concepts be the result of a greater facilitation effect in the negative semanticallyrelated condition (e.g., cut-gash) than in the positive or neutral semantically-related conditions, as there was no significant difference between the means RTs of these three related conditions (negative: $863 \mathrm{~ms}$, positive: $857 \mathrm{~ms}$, neutral: $864 \mathrm{~ms}$ ). Rather, this enhanced priming effect for negative concepts can be explained by the significantly longer RTs in the semantically-unrelated condition for negative targets (e.g. house-viper), compared with the neutral and positive ones. This pattern of longer RTs for the negative targets can be compared to a phenomenon called "negativity bias" (Cacioppo \& Gardner, 1999), which reflects the tendency of subjects to automatically avoid potentially dangerous stimuli. Interestingly, this negativity bias was never observed in the negative semantically-related 
condition, i.e. when the negative target was preceded by a negative and semantically-related prime (e.g., cut-gash). This could mean that, in this condition, the emotional and semantic components of the prime automatically and irrepressibly activated close concepts in the semantic network. Accordingly, relative to the negativity bias in the semantically-unrelated condition, we observed a facilitation effect arising from the association of the concepts' emotionally-negative and semantic components which even managed to overcome the negativity bias of negative concepts. The conception of two separate emotional information processing systems could explain why we observed a negativity bias with the negative and semantically-unrelated targets, but not with the negative and semantically-related targets or with the negative primes. According to LeDoux (1992), the thalamo-amygdaloid pathways allows for the rapid appraisal of a stimulus and thus for an instantaneous response without the involvement of more complex emotional information processing. When a more complex or controlled assessment of emotional stimuli is undertaken, this may require extensive cortical information processing. Apart from the "negativity bias" explanation, the longer RTs in the negative and unrelated condition could conceivably be explained by the intervention of the attentional processes (expectancy mechanisms or postlexical semantic matching processes) that are sometimes observed in priming tasks, although our paradigm was specifically designed to avoid these strategic processes through the use of automaticity criteria (low proportion of related words, short SOA, low attention to the prime, same proportion of word and nonword targets; Posner \& Snyder, 1975; Neely, 1991).

The RTs and priming effects of the positive valence stimuli were different from those of the negative stimuli but not dissimilar to those of the neutral stimuli. This kind of result is often reported in affective priming studies and is sometimes explained by the stimuli's degree of emotional arousal (i.e. how soothing or exciting they are): it is generally difficult to match negative stimuli with positive ones in terms of arousal level, as negative stimuli often yield 
higher arousal scores than positive stimuli (e.g. Lang et al., 1993; Padovan \& Versace, 1998; Canli et al., 2002; Padovan, Versace, Thomas-Antérion, \& Laurent, 2002; Kuchinke et al., 2005; see Zald, 2003, for a review). This is exactly what we found in a statistical analysis of the emotional words used in the present study, which showed that the negative words had a higher level of arousal than the positive ones. Ochsner (2000) considers that the arousal dimension may be particularly important, notably in terms of physiological responses to the stimuli. This could reflect differences in the perception of emotional stimuli: subjects often respond with greater intensity to negative stimuli (negativity bias) (see Kensinger \& Corkin, 2003).

In a study of $\mathrm{AD}$ patients, Kensinger, Anderson, Growdon and Corkin (2004) showed that the patients' ratings of emotional content were similar to those provided by young and older adults: the AD patients were not impaired in their ability to perceive emotional valence and arousal. Similarly, in our study, Izard's emotional self rating scale (see Subjects section) showed that the AD patients seemed to react to emotional concepts in the same way as the control subjects, as the two groups had similar patterns of lexical decision scores relating to emotional valence (no significant interaction between group and emotional condition). This result suggests that although lesions of the amygdala lead to deficits in the recognition and processing of emotional - especially negative - stimuli (LeDoux, 1992; Adolphs, Tranel, Damasio, \& Damasio, 1994), these lesions may be too minor at this stage of the disease to impair the emotional and automatic processing of words.

Although patients and controls displayed similar emotional patterns, the AD patients demonstrated a significant hyperpriming effect, whatever the concepts' affective condition. The findings of several previous semantic priming studies (Chertkow et al., 1989; Giffard et al., 2001, 2002) had led us to expect this paradoxical phenomenon concerning non-emotional coordinate concepts. Conflicting hypotheses have been advanced to explain this hyperpriming 
effect of non-emotional stimuli. According to Nebes et al. (1989), hyperpriming is simply an artefact of a general slowdown in $\mathrm{AD}$ : the slower the patient's responses, the greater the semantic priming effects. Results of our previous studies (Giffard et al., 2001, 2002) do not support this explanation, however. Using Pearson's correlation coefficient, we failed to find any significant relationship between the magnitude of priming effects and RTs. Furthermore, in the present study, semantic priming effects were expressed as a percentage of the unrelated condition RT, thus minimising any effect of slowing on the size of the priming effect. According to other authors (Hartman, 1991; Ober et al., 1991; Silveri et al., 1996; Bell et al., 2001), hyperpriming may simply occur in some experimental conditions which encourage subjects to develop attentional strategies (prelexical expectancy or postlexical semantic matching processes). In a meta-analysis, Ober and Shenaut (1995) observed that hyperpriming mainly occurred in paradigms bringing these attentional processes into play (long SOAs, high proportions of related word pairs and of nonwords). Among other things, attentional processes involve divided attention and working memory, and patients with $\mathrm{AD}$ are known to have considerable difficulty in dividing their attention between concurrent cognitive operations. Thus, when semantic priming tasks involve long SOAs, a high proportion of related pairs or a high proportion of nonword targets, the patients (like normal subjects) attempt to divide their attention between generation, search and decision processes. However, these multiple cognitive operations hamper their impaired working memory, especially for pairs in which the words are unrelated and in which the potential targets have to be inhibited. This probably creates a doubt in the patient's mind about the decision that is required of them ("yes" the target is a word, or "yes" the target is related to the prime). This confusion is then reflected in a greater difference between the RTs for unrelated targets and for targets related to the prime (due mainly to increased slowing for unrelated pairs) for AD patients compared with controls (i.e. hyperpriming). In our study, the protocol was adjusted ( $\mathrm{SOA}=250 \mathrm{~ms}, 20 \%$ related 
pairs, responses for targets only, same proportions of word and nonword targets) so as not to encourage the subjects to adopt expectancy or postlexical processes.

We believe that hyperpriming reflects the deterioration in semantic memory and, more specifically, a storage deficit for specific attributes (Giffard et al., 2001, 2002): from the onset of the dementia, semantic representations gradually deteriorate, affecting specific attributes first, with initial preservation of general knowledge (Martin \& Fedio, 1983). This makes it increasingly difficult to distinguish between coordinate concepts, as they share the same preserved superordinate category, while their specific attributes, which allow them to be told apart, are lost. Hyperpriming can effectively be regarded as repetition priming (where the prime and target are the same), whose effects have a greater magnitude (Martin, 1992). Moreover, like Chertkow et al. (1989), we had previously observed an obvious hyperpriming effect in patients who performed poorly on an explicit semantic memory task featuring naming and questions involving superordinate and attribute knowledge of concepts (Giffard et al., 2001).

Concerning priming effects for emotional concepts, we also observed a hyperpriming effect. Furthermore, it was greater than for the neutral concepts. It can be assumed that, like neutral concepts, emotional concepts can deteriorate (i.e. loss of specific attributes), and as semantically related primes and targets share the same emotional connotation, this strengthens the similarity between them, making them much closer than non-emotional material. Even when concepts are emotional, some of their specific semantic attributes may be lost to AD patients. For example, when the prime viper is presented, its negative emotional connotation occurs instantaneously, but some of its semantic attributes (has a $V$ on its head, bites, is generally small) remain inaccessible for the patients. When the emotionally- and semantically-related target cobra is presented next, the emotional component and the general knowledge (snake, is dangerous, slithers, etc.) of this concept will have been pre-activated by 
the prime that has a similar affective connotation and superordinate information. The specific features of the cobra concept (spreads out its neck, is long, lives in Asia and Africa) may, however, be lost. Therefore, compared with semantic priming involving non-emotional material, emotionally-related words lead to much greater hyperpriming as, in this condition, the affective value is another common component that makes the concepts much more difficult to tell apart for AD patients. As the priming effects were pathological with emotional words (hyperpriming), we suggest that although the preserved emotional processes cannot prevent the semantic deterioration of emotional words from occurring, they nonetheless strengthen the semantic relationship between close emotional concepts compared with neutral ones.

We can assume here that the emotional components of concepts do not represent semantic features as such, but instead bring about general arousal processing that cannot protect against the loss of distinctive semantic features. Emotional features seem to have a larger and more diffuse impact on word processing than neutral semantic features. The quick and automatic extraction of the emotional components of words appears to lead to an amplification of cortical processing, thus increasing the probability of crossing a minimum threshold of neuronal activation subserving access to related words. Our results show that this emotional process is preserved in AD and may even help patients to bind semantically close emotional concepts together more tightly. 
Acknowledgements. We wish to thank Ms Magali Lefèvre and Ms Céline Ben Bouali for recruiting the patients and assisting in this study, and the referees for their constructive comments. 


\section{References}

Adolphs, R., Tranel, D., Damasio, H., \& Damasio, A. (1994). Impaired recognition of emotion in facial expressions following bilateral damage to the human amygdala. Nature, $372,669-672$.

Albert, M. S., Cohen, C., \& Koff, E. (1991). Perception of affect in patients with dementia of the Alzheimer type. Archives of Neurology, 48, 791-795.

Bargh, J. A., Chen, M., \& Burrows, L. (1996). Automaticity of social behavior: direct effects of trait construct and stereotype-activation on action. Journal of Personality and Social Psychology, 71, 230-244.

Bargh, J. A. (1997). The automaticity of everyday life. In R. S. Wyer (Ed.), The automaticity of everyday life: Advances in social cognition (Vol. 10, pp. 1-61). Mahwah, NJ: Erlbaum.

Bell, E. E., Chenery, H. J., \& Ingram, J. C. L. (2001). Semantic priming in Alzheimer's dementia: Evidence for dissociation of automatic and attentional processes. Brain and Language, 76, 130-144.

Bucks, R. S. \& Radford, S. A. (2004). Emotion processing in Alzheimer's disease. Aging and Mental Health, 8, 222-232.

Budson, A. E., Todman, R. W., Chong, H., Adams, E. H., Kensinger, E. A., Krangel, T. S., \& Wright, C. I. (2006). False recognition of emotional word lists in aging and Alzheimer's disease. Cognitive and Behavioral Neurology, 19, 71-78.

Cacioppo, J. T. \& Gardner, W. L. (1999). Emotion. Annual Review of Psychology, 50, 191214.

Canli, T., Desmond, J. E., Zhao, Z., Gabrieli, J. D. (2002). Sex differences in the neural basis of emotional memories. Proceeding of the National Academy Sciences of the United States of America, 99, 10789-10794. 
Chertkow, H., Bub, D., Bergman, H., Bruemmer, A., Merling, A., \& Rothfleisch, J. (1994). Increased semantic priming in patients with dementia of the Alzheimer's type. Journal of Clinical and Experimental Neuropsychology, 16, 608-622.

Chertkow, H., Bub, D., \& Seidenberg, M. (1989). Priming and semantic memory loss in Alzheimer's disease. Brain and Language, 36, 420-446.

Collins, A. M., \& Loftus, E. F. (1975). A spreading activation theory of semantic processing. Psychological Review, 82, 407-428.

De Houwer, J., Hermans, D., Rothermund, K., \& Wentura, D. (2002). Affective priming of semantic categorization responses. Cognition and Emotion, 16, 643-666.

Devlin, J. T., Gonnerman, L. M., Andersen, E. S., \& Seidenberg, M. S. (1998). Categoryspecific semantic deficits in focal and widespread brain damage: a computational account. Journal of Cognitive Neuroscience, 10, 77-94.

Fazio, R. H., Sanbonmatsu, D. M., Powell, M. C., \& Kardes, F. R. (1986). On the automatic activation of attitudes. Journal of Personality and Social Psychology, 50, 229-238.

Ferrand, L., Ric, F., \& Augustinova, M. (2006). Quand "Amour" amorce "Soleil" (ou pourquoi l'amorçage affectif n'est pas un (simple) cas d'amorçage sémantique) [Affective priming: A case of semantic priming?]. L'Année Psychologique, 106, 79-104.

Folstein, M. F., Folstein, S. E., \& McHugh, P. R. (1975). "Mini-mental state". A practical method for grading the cognitive state of patients for the clinician. Journal of Psychiatric Research, 12, 189-198.

Gaillard, R., Del, C. A., Naccache, L., Vinckier, F., Cohen, L., \& Dehaene, S. (2006). Nonconscious semantic processing of emotional words modulates conscious access. Proceedings of the National Academy of the Sciences of the United States of America, $103,7524-7529$. 
Giffard, B., Desgranges, B., \& Eustache, F. (2005). Semantic memory disorders in Alzheimer's disease: clues from semantic priming effects. Current Alzheimer Research, 2, 425-434.

Giffard, B., Desgranges, B., Kerrouche, N., Piolino, P., \& Eustache, F. (2003). The hyperpriming phenomenon in normal aging: A consequence of cognitive slowing? Neuropsychology, 17, 594-601.

Giffard, B., Desgranges, B., Nore-Mary, F., Lalevee, C., Beaunieux, H., de la Sayette, V. et al. (2002). The dynamic time course of semantic memory impairment in Alzheimer's disease: clues from hyperpriming and hypopriming effects. Brain, 125, 2044-2057.

Giffard, B., Desgranges, B., Nore-Mary, F., Lalevee, C., de la Sayette, V, Pasquier, F. et al. (2001). The nature of semantic memory deficits in Alzheimer's disease: new insights from hyperpriming effects. Brain, 124, 1522-1532.

Giffard, B., Laisney, M., Mézenge, F., de la Sayette, V., Eustache, F., \& Desgranges, B. (2008). The neural substrates of semantic memory deficits in early Alzheimer's disease: Clues from semantic priming effects and FDG-PET. Neuropsychologia, 46, 1657-1666.

Hartman, M. (1991). The use of semantic knowledge in Alzheimer's disease: Evidence of impairment of attention. Neuropsychologia, 29, 213-228

Hermans, D., De Houwer, J., \& Eelen, P. (1994). The affective priming effect: Automatic activation of evaluative information in memory. Cognition and Emotion, 8, 515-533.

Hodges, J. R. (2006). Alzheimer's centennial legacy: origins, landmarks and the current status of knowledge concerning cognitive aspects. Brain, 129, 2811-2822.

Hodges, J. R., Salmon, D. P., \& Butters, N. (1992). Semantic memory impairment in Alzheimer's disease: failure of access or degraded knowledge? Neuropsychologia, 30, 301-314. 
Hutchinson, K. A. (2003). Is semantic priming due to association strength or feature overlap? A microanalytic review. Psychonomic Bulletin \& Review, 10, 785-813.

Innes-Ker, A., \& Niedenthal, P. M. (2002). Emotion concepts and emotional states in social judgment and categorization. Journal of Personality and Social Psychology, 83, 804-816.

Kensinger, E. A., Anderson, A., Growdon, J. H., \& Corkin, S. (2004). Effects of Alzheimer disease on memory for verbal emotional information. Neuropsychologia, 42, 791-800.

Kensinger, E. A., \& Corkin, S. (2003). Memory enhancement for emotional words: are emotional words more vividly remembered than neutral words? Memory and Cognition, $31,1169-1180$.

Klauer, K. C., \& Musch, J. (2003). Affective priming: Findings and theories. In J. Musch, \& K. C. Klauer (Eds.), The psychology of evaluation: Affective processes in cognition and emotion (pp. 7-49). Mahwah, NJ: Lawrence Erlbaum.

Kuchinke, L., Jacobs, A. M., Grubich, C., Võ, M. L., Conrad, M., \& Herrmann, M. (2005). Incidental effects of emotional valence in single word processing: an fMRI study. Neuroimage, 28, 1022-1032.

Lang, P. J., Greenwald, M. K., Bradley, M. M., Hamm, A. O. (1993). Looking at pictures: affective, facial, visceral, and behavioral reactions. Psychophysiology, 30, 261-273.

LeDoux, J. (1992). The Emotional Brain. New York: Simon \& Schuster.

Lucas, M. (2000). Semantic priming without association: a meta-analytic review. Psychonomic Bulletin \& Review, 7, 618-630.

Martin, A. \& Fedio, P. (1983). Word production and comprehension in Alzheimer's disease: the breakdown of semantic knowledge. Brain and Language, 19, 124-141. 
Martin, A. (1992). Semantic Knowledge in patients with Alzheimer's disease: Evidence for degraded representation. In L.Bäckman (Ed.), Memory functioning in dementia (pp. 119134). Amsterdam: Elsevier Science Publishers BV.

Mattis, S. (1976). Mental status examination for organic mental syndrome in the elderly patient. In L. Bellack, \& T. Katasu (Eds.), Geriatric psychiatry: A handbook for psychiatrists and primary care physicians (pp. 77-120). New York: Grune and Stratton.

McKhann, G., Drachman, D., Folstein, M., Katzman, R., Price, D., \& Stadlan, E. M. (1984). Clinical diagnosis of Alzheimer's disease: report of the NINCDS-ADRDA Work Group under the auspices of Department of Health and Human Services Task Force on Alzheimer's Disease. Neurology, 34, 939-944.

McRae, K., Seidenberg, M. S., \& De Sa, V. R. (1997). On the nature and scope of feature representations of word meaning. Journal of Experimental Psychology, General, 126, 99130.

Murphy, S. T. \& Zajonc, R. B. (1993). Affect, cognition, and awareness: affective priming with optimal and suboptimal stimulus exposures. Journal of Personality and Social Psychology, 64, 723-739.

Naccache, L., Gaillard, R., Adam, C., Hasboun, D., Clemenceau, S., Baulac, M. et al. (2005). A direct intracranial record of emotions evoked by subliminal words. Proceedings of the National Academy of the Sciences of the United States of America, 102, 7713-7717.

Nebes, R. D., Martin, D. C., \& Horn, L. C. (1984). Sparing of semantic memory in Alzheimer's disease. Journal of Abnormal Psychology, 93, 321-330.

Neely, J. H. (1991). Semantic priming effects on visual word processing: a selective review of current findings and theories. In D. Besner, \& G. Humphreys (Eds.), Basic processes in reading: Visual word recognition (pp. 264-336). Hillsdale, NJ: Lawrence Erlbaum. 
New, B., Pallier, C., Ferrand, L., \& Matos, R. (2001). Une base de données lexicales du français contemporain sur internet : LEXIQUETM $[$ A lexical database for contemporary french : LEXIQUETM]. L'année psychologique, 101, 447-462.

Ober, B. A., \& Shenaut, G. K. (1995). Semantic priming in Alzheimer's disease: Metaanalysis and theoretical evaluation. In P. A. Allen \& T. R. Bashore (Eds.), Age differences in word and language processing (pp. 247-271). Amsterdam: Elsevier Science Publishers BV.

Ober, B. A., Shenaut, G. K., Jagust, W. J., \& Stillman, R. C. (1991). Automatic semantic priming with various category relations in Alzheimer's disease and normal aging. Psychology and Aging, 6, 647-660.

Ochsner, K. N. (2000). Are affective events richly recollected or simply familiar? The experience and process of recognizing feelings past. Journal of Experimental Psychology, General, 129, 242-261.

Ouss, L., Carton, S., Jouvent, R., \& Widlocher, D. (1990). [French translation and validation of Izard's differential emotion scale. Study of the verbal qualification of emotions]. Encephale, 16, 453-458.

Padovan, C., \& Versace, R. (1998). The representation of emotion in long term memory. In G. Ritschard, A. Berchtold, F. Duc, \& D. A. Zighed (Eds.), Apprentissage: Des principes naturels aux méthodes artificielles (pp.111-123). Paris: Hermès.

Padovan, C., Versace, R., Thomas-Anterion, C., \& Laurent, B. (2002). Evidence for a selective deficit in automatic activation of positive information in patients with Alzheimer's disease in an affective priming paradigm. Neuropsychologia, 40, 335-339.

Pecchinenda, A., Ganteaume, C., \& Banse, R. (2006). Investigating the mechanisms underlying affective priming effects using a conditional pronunciation task. Experimental Psychology, 53, 268-274. 
Posner, M., \& Snyder, C. (1975). Attention and cognitive control. In R. L. Solso (Ed.), Information processing and cognition: The Loyola Symposium (p. 55-85). Hillsdale, NJ: Lawrence Erlbaum.

Salmon, D. P., Butters, N., \& Chan, A. S. (1999). The deterioration of semantic memory in Alzheimer's disease. Canadian Journal of Experimental Psychology, 53, 108-117.

Schirmer, A., Zysset, S., Kotz, S. A., \& von Cramon, D. Y. (2004). Gender differences in the activation of inferior frontal cortex during emotional speech perception. NeuroImage, 21, $1114-1123$.

Silveri, M. C., Monteleone, D., Burani, C., \& Tabossi, P. (1996). Automatic semantic facilitation in Alzheimer's disease. Journal of Clinical and Experimental Neuropsychology, 18, 371-382.

Versace, R., Augé, A., Thomas Antérion, C., \& Laurent, B. (2002). Affective priming effects in the left and right cerebral hemispheres in patients with Alzheimer's disease. Aging, Neuropsychology, and Cognition, 9, 127-134.

Wentura, D. (1999). Activation and inhibition of affective information: Evidence for negative priming in the evaluation task. Cognition and Emotion, 13, 65-91.

Zajonc, R. B. (1980). Feeling and thinking: Preferences need no inferences. American Psychologist, 35, 151-175.

Zald, D. H. (2003). The human amygdala and the emotional evaluation of sensory stimuli. Brain Research, Brain Research Reviews, 41, 88-123. Review.

Zhang, Q., Lawson, A., Guo, C., \& Jiang, Y. (2006). Electrophysiological correlates of visual affective priming. Brain Research Bulletin, 71, 316-323. 